\title{
TRANSLATION: A CULTURAL SLIDE SHOW
}

\author{
B. HARIHARAN
}

Abstract: In this paper, I propose to look at translation from at least three perspectives: Translation as a personal enterprise, as a cultural enterprise with a social missionand and translation as cartographing social demography or translation as public enterprise. It is obvious that we obtain here translated texts that are movements in cultural description that shape our living. The paper discusses the cultural implications of a book titled Into the World of Kutiyattam published by Natanakairali in Kerala, and explores the articulation of public space where translation takes place in a significant way, in particular, Mananchira Square in Calicut city. It is imperative to recognize these sites as cultural texts if we are to arrive at a description of the cultural matrix that we help to translate every instant.Rather than limit the idea of translation, this paper proposes to extend and push the implications of the term to different sites in my cultural experience.

\section{Introduction}

Translation, Translation Studies, and translation theories are variously involved in the shaping of cultural discourses. It is a general practice to recognize the original text and the translated text in translation theory, wherein what is 
called the 'text' is invariably made of words. Much the same is true when one translates from one language into another. Writing his introduction to his book, Rethinking Translation, Lawrence Venuti (Venuti 1992) draws attention to a number of questions that concern the translator and translation. He writes, "To be a 'leading' translator today is not only to produce translations that are highly accomplished, favourably reviewed, and award-winning, but it also means sheer quantity, executing numerous projects, practicing translation as a steady if meager source of income, gaining an economic advantage over other translators in the competition for foreign texts and the negotiation of fees"(Venuti1992:1). He also laments the fact that translators are not "critically self-conscious writers who develop an acute awareness of the cultural and social conditions of their work" (ibid:1). It is obvious here that the reference is to literary texts for the questions he addresses and the discussions available on translation are invariably on the attendant problems, challenges, and issues relating to literary texts.

For my purposes, I wish to understand 'translation' not merely in linguistic terms, caught invariably in the binary of the original and translated text. I use the word 'text' not just in literary terms, as, say, a poem written by K.G. Sankara Pillai in Malayalam that is translated into English or some other language. A dream, or an orthodox tradition handed down from generation to generation in a text may also be translated with an 'acute' awareness of the cultural and social conditions, an awareness that is free of the limitations of binarism. Again, the city, for instance, is a text for me subject to translation. I will be using these two terms in a flexible manner to facilitate 
discussion of issues. I shall also look at the possible impact of translation on texts.

For didactic purposes the paper is divided into three parts so as to address three specific aspects of translation. They are:

(a) Translation as a personal enterprise

(b) Translation as a cultural enterprise with a social mission

(c) Translation as cartographing social demography or translation as a public enterprise.

The paper is an exposition of my personal experience with a remarkable institution in Kerala. In Irinjalakuda in Kerala, there is a Research and Performing Centre for Traditional Arts called Natanakairali, which houses a Gurukulam that trains students in the hoary and ancient Sanskrit theatre called Kutiyattam. This is one of the oldest, living and surviving forms of theatre in the world. As part of the Documentation of Kutiyattam Series, the director of Natanakairali G. Venu was bringing out his memoirs in Malayalam and English and wrote to me asking whether I would translate the manuscript from Malayalam into English, a suggestion to which I promptly agreed. As I was translating the manuscript, there were some questions I had on the reason for such an enterprise and my role in the project.

For me, the project was not merely the change of the linguistic script from Malayalam to English. As I was aware of 
the kind of activities and programmes of Natanakairali, I saw the translation was more for the promotion of the art form at an international level. It was also a tribute to the living legend in Kutiyattam, Guru Ammannur Madhava Chakyar. The job of the translator at this point was to market culture to a larger and diverse audience. For me as a boy, Kutiyattam figured in a popular Malayalam song, in the magnificent paint that described the face of the character, and in the dim awareness that it is an art form performed in the koothambalam of the temple as part of a ritual. I had not seen any live performance until I started my teaching career. There is a popular view that Kutiyattam is difficult to understand. What is even more curious is that the State Government has done little to recognize the value of this heritage. Nor has it acknowledged Guru Ammannur's contribution to theatre.

It was in this context that the importance of the translation assumed significance for me. It is true that subsequent Governments in Kerala have promoted tourism with their catchy slogan, aggressively marketing cultural packages for tourists. With their bonsai versions of Kathakali and Theyyam, the department of tourism was always going global. The translation project was, in this context, an attempt from the grass root level to consolidate further the work at Natanakairali. However, translation as a cultural enterprise came under scrutiny as the work progressed. For, the question that popped up most was whether translation transforms culture into commodity. The tourism department had effected their translation of other art forms for immediate un-reflexive consumption. Here was the danger of translation becoming mutilation, striking at the form and language of the art form. 
It is important to be aware that translations do become saleable products, especially when there is an agreement with the publisher. And as with any other book, the publishing industry has an important stake in the case of translations, more so because they effect a further transition of the book into cultural expression, into commodity. It is clear that the conditions that are instrumental in any translation project like the involvement of the publisher, the choice of the text, the culture, the language of the text, the reputation of the author, and of the translator, and so on, decide the circulation of the finished product and with that the economics and marketability of this cultural dissemination. In the present case, the book was to be brought out by Natanakairali as part of its larger attempt at documentation and with a specific target audience. Though the commodification of books in the present distribution system is inevitable, though the sale of this book may be networked with the publications industry, the inevitable nexus between translation and commodification has to be addressed earnestly.

I would now like to touch briefly upon one other translation done for Natanakairali on the hand gestures in Kathakali. Translation generally involves printed texts that form the original for the intervention of the translator into another language. But when it comes to a proto-lingual text, how does one discuss the process of translation? What is the experience when one translates proto-languages? G. Venu had written down in Malayalam notations for some gestures in Kathakali that had to be translated into English. But then for many of the hand gestures, he would show them and I had to translate all the gestures into English on the spot. I have no training whatsoever in Kathakali or other art forms and I was 
aware that what I was seeing was the result of years of training and research in the field.

The question of cultural production for mass consumption did not arise in this translation. This was partly the elaboration of his earlier publication in Malayalam. I realized then that translation does not always involve written texts, that what one generally understands as text needs to be revised. Equally important was the awareness that Venu's book The Language of Kathakali is incidentally made available in English, and that the experience and emotion communicated through hand gestures are beyond the printed word in translation. The lack of narrative, or a coherent story line and the technicality of the printed text seem to point here to a rather utilitarian function for the translator and translation.

\section{II}

A translation can reveal other translated intentions. This was an insight I gained as I read G. Venu's manuscript with the idea of translating it in mind. A translation need not always be an act of negotiation with or intervening in a text to re-create and rewrite it in a different language. It could be manifest as a cultural enterprise with a social bearing. Such flexibility in the usage helps locate the idea of translation at the level of social commitment. In Into the World of Kutiyattam (Venu 2002), Venu narrates the establishment of a kalari by Chachu Chakyar: "Chachu Chakyar wished fervently to see Koothu and Kutiyattam triumph over time. Impelled by this desire he organized a Kutiyattam Kalari (Training centre) in his own household. He relied entirely on his own modest means of maintaining it" (Venu 2002:38). In 1982 with the 
help of Sangeet Natak Akademi, a Gurukulam was established in Venu's rented house. The future of this theatre seemed very bleak as recently as the 1970's. That Venu's translation of the result of a training programme he could only imagine after witnessing Ammannur's performance speaks of a cultural consciousness necessary for every translator: "It became my life's dream to mould a young generation of artistes trained in this art by imparting the same rigorous training received by Ammannur"(ibid:17).

The Kalari started by Chachu Chakyar was being used then as living quarters. The Gurukulam emerged as a translation of a dream Chachu Chakyar had. This is an important development in the history of Kutiyattam, especially with the orthodox Chakyar families, as the art form was traditionally handed down from generation to generation within the family. The Gurukulam translated Chachu Chakyar's wish to "triumph over time" in the new school where training is given to non-Chakyars. It is also to be mentioned that the Kerala Kalamandalam has a Kutiyattam department; the Margi School in Trivandrum also trains aspirants in this theatre.

There are far reaching cultural implications here, for only Chakyars are permitted to perform inside the Koothambalam in temples. There was an outcry when Venu had his Arangettam in Trivandrum in the 1984 Kutiyattam festival. Generally, Kutiyattam is performed only in the Koothambalam. Writes Venu, "With a lot of heartache Madhava Chakyar and myself decided to have the next Kutiyattam festival in a convenient place outside the temple which could attract all lovers of art"'(ibid:61). The Gurukulam has trained the younger generation and has festivals every year 
at Natanakairali so that they get good stage exposure. The younger generation has now performed in a number of countries, perhaps making what was once confined to the Koothambalam an intense art form amenable to translation across cultures. Translation, in this sense, becomes transformation of an entire way of life of the Chakyar family as well as the theatre.

What distinguishes this clearly from the bonsaification of art is that this theatre experience is not opted into market economics, focused as it is on the continuation of a theatre tradition that was highly stylized and yet intensely emotional. So, at the Festival of India in London, at the Riverside Studio, London, Guru Ammannur's troupe performed Balivadham.

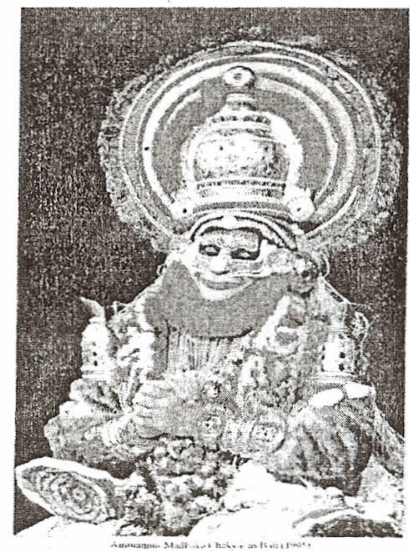

What is unique about this production is that Bali's death scene is done elaborately. The theatre director suggested that, "Such an elaborate enactment of death scene will never be appreciated by our audience. It will be better if you reduce its duration"(ibid:31). But Guru Ammannur who did the role of Bali did not comply. "The theatre director could not believe 
what he saw; the packed audience sat with bated breath till the end of the death scene" (ibid:31). Kenneth Rae of The Guardian wrote: "...one of the bravest and most outrageous pieces of acting I have ever seen. Who else would dare take 15 minutes to die on stage, and get away with it?"(ibid:31).

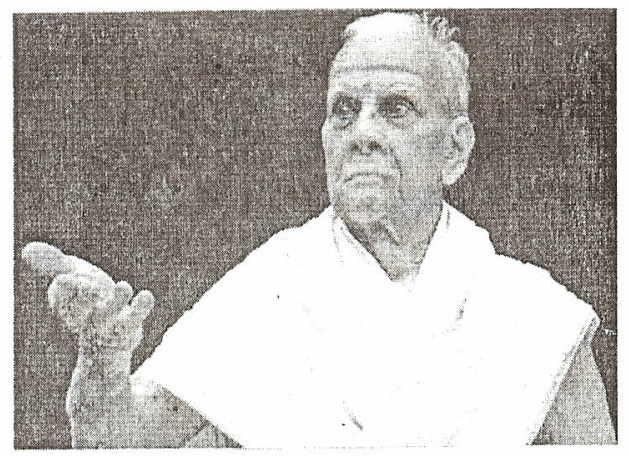

The translation of a family tradition into a communal heritage and the recognition of a need to preserve and promote art are underscored here. It is the same impetus seen in the staging of Ashokavanikangam and Jatayuvadham after a very long time. The impetus goes back to the school which was started in 1982. There is at once a translation of performance and translation of training in the arts here.

This can be illustrated with the most recent body of translation to have appeared on the stage. It is surprising that until 2001 Kalidasa's Sakuntalam was never staged in Kutiyattam. There were two different stage manuals for two different acts in the play. But no complete play was staged spread over twelve hours for four days from January 5 - 8, 2002. If the popularity of Sakuntalam Kutiyattam is gauged, it is suggestive of the cultural consciousness that augments the training and performance giving direction to the translation 
that charts the course of this theatre. With the performance of Kalidasa's play, a border was crossed.

In a sense, translation is a form of border crossing. A quick look at the World Theatre Project that also involves the Gurukulam, and Natanakairali in this theatre experiment might help. It must be said that though the cultural continuation of Kutiyattam was maintained in the translation of family tradition and temple ritual, theatre experience is certainly translated into the dynamics of globalization. In 1998-99, the World Theatre Workshop was held at Natanakairali, Irinjalakuda.

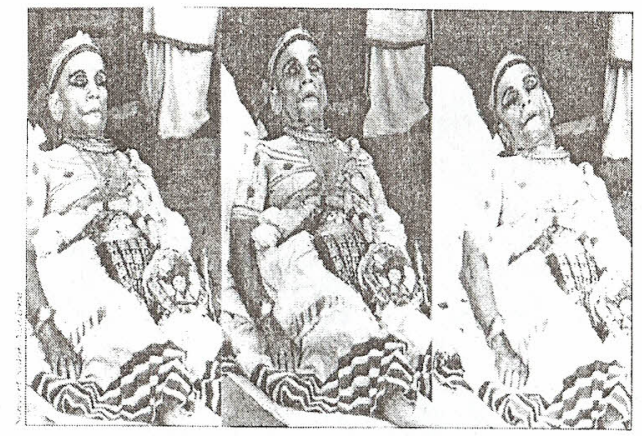

Interestingly Guru Ammannur was very active in training the participants in the workshop. The idea that came of it was to "facilitate an opportunity for theatre artistes from different backgrounds to work together aiming at a production as an experiment and as part of the experience to understand each other"(102). They had an improvised production in Sweden in 1999 called "East of the Sun, West of the Moon" which was based on a classic Chinese text "Journey to the West". The World Theatre Project may not be the old story of the East meeting the West; it is the continuation of the ongoing 
translation of the experience of theatre that had come near extinction without anyone to continue the tradition of the training available in the Abhinaya Kalari (training laboratory) at the Kodungallor Palace inherited by the Ammannur Chakyars. As part of this ongoing translation, was set up an Abhinaya Kalari funded by the Japanese Foundation Asia Centre. The fact that this continual cultural translation had made a mark in the preservation and promotion of Kutiyattam is well borne out in the recognition that the UNESCO gave it in May 2001.

\section{Oral and Intangible Heritage of Humanity}

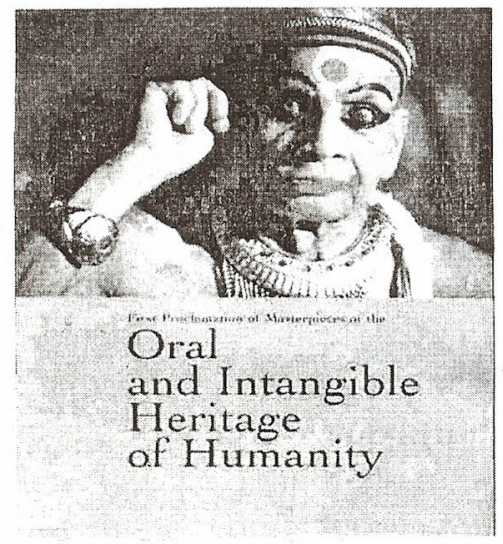

III

I now propose to look at a third dimension of the phenomenon of translation. Since I do not confine the term 'translation' to the printed word, I shall be looking at an area 
that concerns the urban geographer. The city is a cultural text. My attempt here is to look at the ways in which city spaces are translated to serve different purposes. With this, of course, are changed life styles of people. Once familiar, landmarks, names, leisure, hobbies, speak in a different tongue.Everything a city has speaks in a different tongue. Here 'translation' pushes the cultural limits of experience in the transcreation of the city as a different experience.

Calicut City: Mananchira is a large pond in the heart of the city of Calicut. It was the bathing tank of the members of the Zamorin's household.

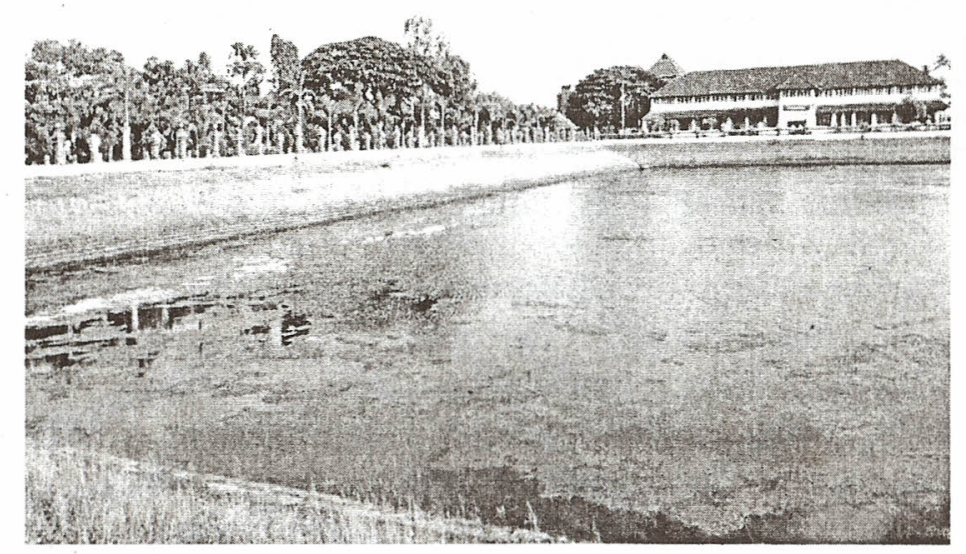

As the city grew, there were changes in the cityscape and Mananchira became the heart of the city. Today, the heart of the city is trans-created into a beautiful park called Mananchira Square. It was thrown open to the public in 
November 1994. The Tagore and Ansari Park separated from the pond by a road on one side, and on the south of it, the maidan (ground) separated by a road defined the site as an identifiable landmark. Now all these are fused, walled in, and renamed as Mananchira Square.

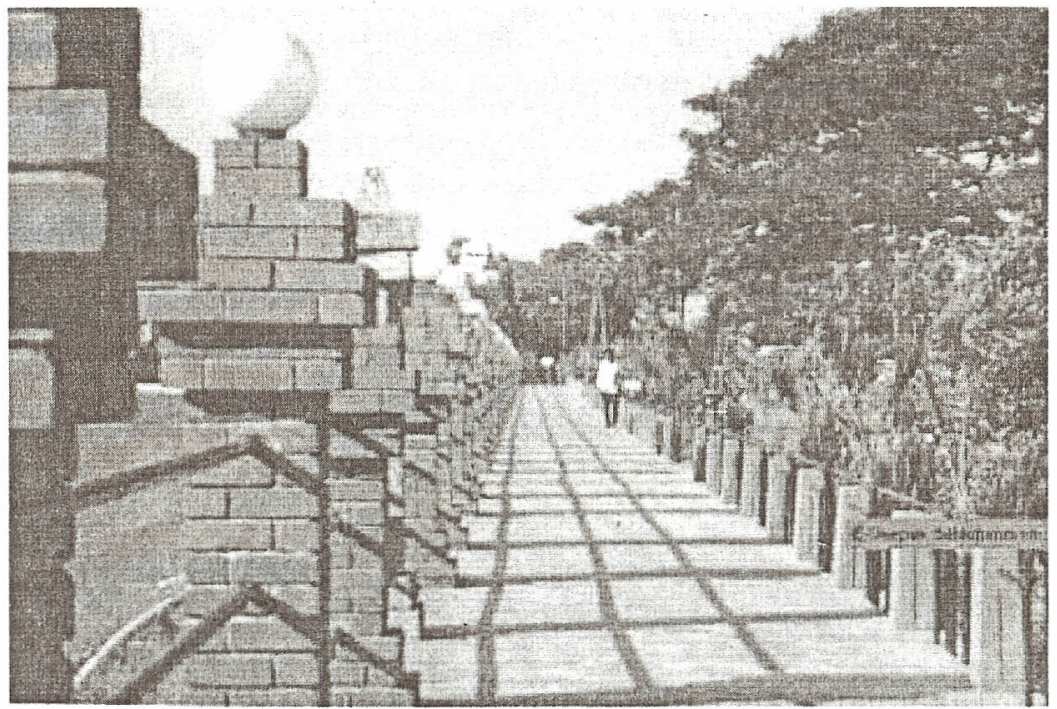

The description of this text will be incomplete without some additional details: The Square has two statues, one of V.K. Krishna Menon and another one called Padayali. New trees have been planted all around, and there are two entrances, one across the Pattala palli (military mosque) and the other across from the commonwealth factory, both designed to reminisce the Huzur Kacheri building (which was the head quarters of the East India Company and later of the Malabar Presidency) which was demolished to be replaced by the new mammoth LIC building. The exit is across the model school/old law college junction built in a similar style (tiled 
roof, white/peach colonial walls, a typical Keralite touch). (Thyagarajan's Mananchira Square). There is a musical fountain at the north end of the Square, and an open-air theatre Kalakrithi, a music stage and concealed speakers.

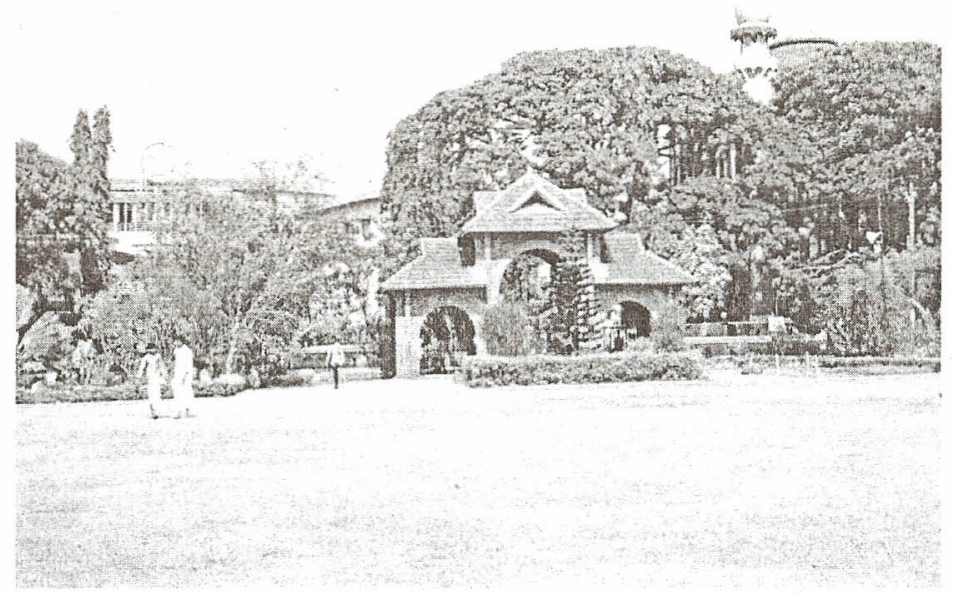

This was called Mananchira Junction. There were annual fairs during the Onam festival, and arts competitions. Indira Gandhi, C.H. Mohammed Koya, Muhammad Ali, Swami Chinmayananda and K.P. Kesava Menon, to name a few, addressed people here. Memories linger in the mind of Sunday cricket matches, football practice, P.T.Usha running her 100 meters apart from her training on the beach, and Gundappa R Viswanath the cricketer hitting a huge six into the sub collectorate building. Even more was the first steps into the world of football, the ground nurturing many a football dream, not just for the city but also for the whole district. The busy centre with buses competing with one another also had in 
their midst the wood barrel water cart carrying water to restaurants.

It is always possible to be nostalgic about familiar landmarks, but the point I want to make is the way in which the cartography of the city changed with this 700-lakh rupees project. The translation, as trans-creation, redefined leisure for the city dweller. The ground and the musical fountain compete with the beach in attracting people. In this sense, translation alters social behaviour; here is clearly the postmodern expression of the city.

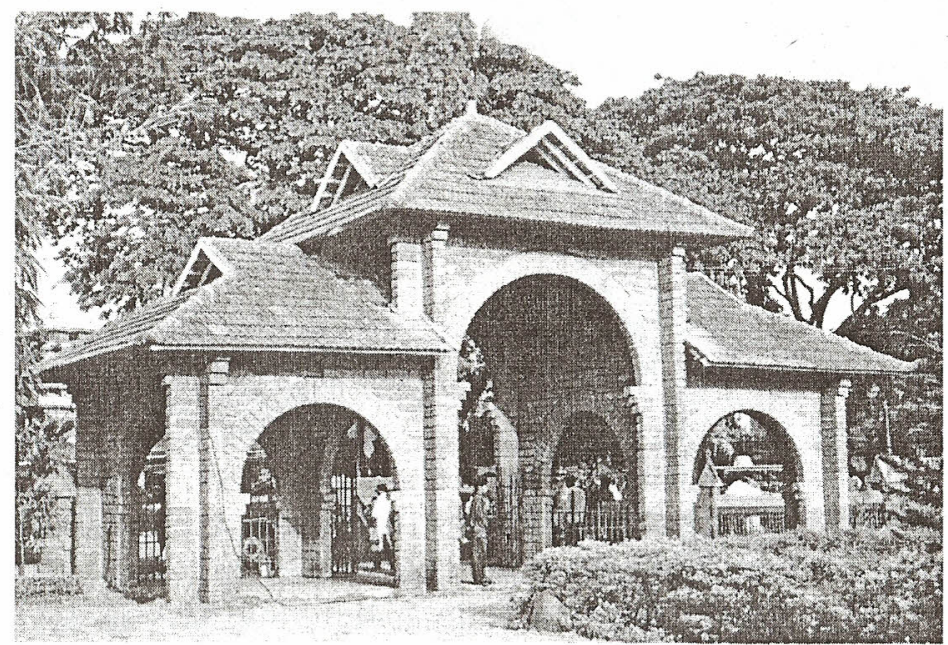

A closer look at the square reveals some other interesting details. "The maidanam has now a green carpet lawn and the whole complex is circled by a laterite (a kind of stone) sculpted wall. The entire complex is circled by 250 lamp posts that are designed in the colonial style and each post will have a pair of lamps." ("Mananchira Square") The lamps were specially cast in North India and are mounted on the laterite wall encircling the pond. One feature of this sort of 
trans-creation is the expression of postmodernism in the design of the city. For one important feature of postmodern architecture is the focus on appearance over substance and purpose. Added to that is a deliberate mixing of diverse features.

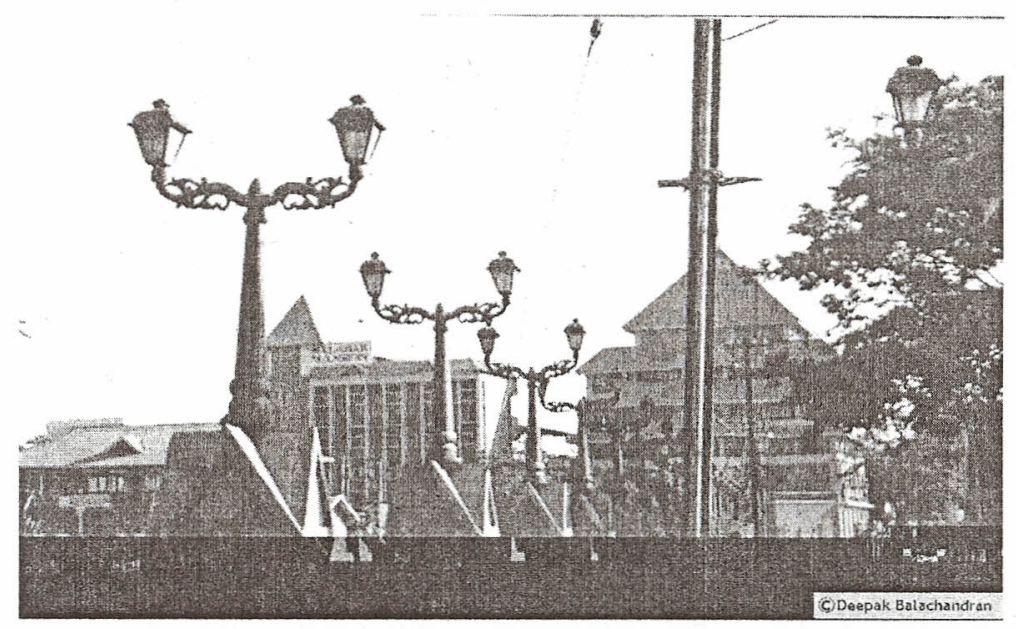

This sort of trans-creation manifests in the new building of the public library. What used to be in my student days a tile-roofed building open for the 'intellectuals' of the city now attracts the middle class and is said to have a larger and wider readership. It is now a multi-purpose building with shops let out in the ground floor, translating space into money as much as leisure and knowledge share the upper rooms. The library building has a structure that is aesthetically pleasing where another dimension of translation manifest itself. Translation of cityscapes brings together styles and references from different periods to create a discourse that draws attention to the way aesthetic refinement is structured. The building has drawn heavily on Laurie Baker and on traditional Kerala 
architecture. Added to that is the exposed laterite that seems to aggressively draw attention to itself.

I would like to draw the reader's attention to one more important structure that has altered the city in a significant way, but before that, let's recall the structure of the temples in Kerala, especially the Vadakkumnathan Temple in Trichur. One should notice the roof that slopes down. Now if we turn our attention to the Planetarium in Calicut, located to the East Mananchira, one notices that it is modeled very much on the architecture of the temple.

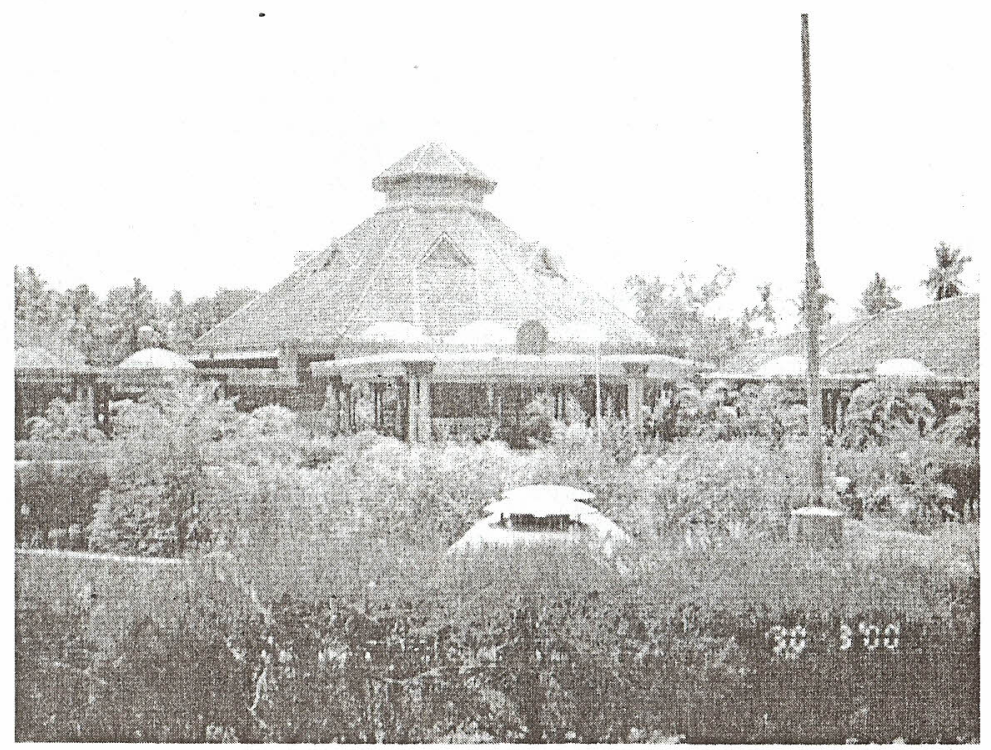

The design of the temple, I would argue, is translated to construct a temple for science. There is a lot of semantic transfer in this translation. This is probably the only planetarium of its kind in the country, which seems to thematically draw attention to science enshrined in a temple. 
This dimension of translation in the public sphere possibly manifests best the change in a people and culture. Only a fuller study of translation in the public sphere will enable an understanding of the cultural discourses that condition the trans-creation of space. A salient point to emerge here is the relation between the consequence of translation and the location of leisure. These trans-creations in the cityscape, however, are neither isolated discourses nor are they closed off to further trans-creations. Similar translations continue to function in the major festivals in the State, in the domestic sphere altering the shape of living. For instance, there are oblique references to the Mananchira Square and the beautification project in a very politically charged Malayalam movie. In a sense, leisure and with that the public is made to confront the politics of translation here.

\section{Conclusion}

Every slide show must end. But translation goes on. In the re-creation of texts in different languages, spaces, situations, memories, newer paradigms, ideologies, politics, are created, subject always to further translation. It is almost Ovidian as texts pull off magnificent changes. And yet, these changes are contextualised, framed well within the cultural space that makes possible the impetus to translate. The effect that a translation has is as important in any theorizing on translation as the problems the translator faces.

\section{References}

Thyagarajan, Subramanian Mananchira Square. 
www.2.cs.cmu.edu/cgi-

bin/finger?tsubram@unix.cc.emory.edu

Venu, G. (2000). The Language of Kathakali. Dance Notation Series, no.2. Irinjalakuda: Natanakairali.

----, (2002). Into the World of Kutiyattam with the Legendary Ammannur Madhava Chakyar. Irinjalakuda: Natanakairali.

Venuti, Lawrence (ed) (1992). Rethinking Translation: Discourse, Subjectivity, Ideology. London and New York: Routledge.

\section{Acknowledgements}

- www.calicutnet.com/calicut/_photogallery/mananchira _square.html

- www.calicutnet.com/calicut/_photogallery/planetarium. html for the photographs on Mananchira.

- Venu.G for Photos on Kutiyattam for the book into the World of Kutiyattam 